Article

\title{
Awareness of Medication-Related Osteonecrosis of the Jaws amongst Dental Professionals in Poland
}

\author{
Monika Teślak ${ }^{1, *(\mathbb{D}, \text {, Hanna Sobczak }}{ }^{2}$, Iwona Ordyniec-Kwaśnica ${ }^{1}$, Barbara Kochańska ${ }^{3}$ (i) \\ and Barbara Drogoszewska ${ }^{2}$ (D) \\ 1 Department of Prosthodontics, Medical University of Gdansk, 80-210 Gdansk, Poland; \\ iwona.ordyniec@gumed.edu.pl \\ 2 Department of Maxillofacial Surgery, Medical University of Gdansk, 80-210 Gdansk, Poland; \\ hanna.sobczak@gumed.edu.pl (H.S.); barbara.drogoszewska@gumed.edu.pl (B.D.) \\ 3 Department of Conservative Dentistry and Endodontics, Medical University of Gdansk, \\ 80-210 Gdansk, Poland; barbara.kochanska@gumed.edu.pl \\ * Correspondence: monika.teslak@gumed.edu.pl; Tel.: +48-600-102-846
}

check for

updates

Citation: Teślak, M.; Sobczak, H.; Ordyniec-Kwaśnica, I.; Kochańska, B.; Drogoszewska, B. Awareness of Medication-Related Osteonecrosis of the Jaws amongst Dental Professionals in Poland. Appl. Sci. 2021, 11, 4821. https://doi.org/ 10.3390/app11114821

Academic Editor: Marcin Kozakiewicz

Received: 5 April 2021

Accepted: 18 May 2021

Published: 24 May 2021

Publisher's Note: MDPI stays neutral with regard to jurisdictional claims in published maps and institutional affiliations.

Copyright: (c) 2021 by the authors. Licensee MDPI, Basel, Switzerland. This article is an open access article distributed under the terms and conditions of the Creative Commons Attribution (CC BY) license (https:// creativecommons.org/licenses/by/ $4.0 /)$.

\begin{abstract}
Background: Medication-Related Osteonecrosis of the Jaws (MRONJ) is a serious complication of antiresorptive therapy. The aim of the study was to assess the level of knowledge and awareness regarding MRONJ among Polish dentists and students of dentistry. Methods: The online self-administered questionnaire was sent out electronically among dentists in Poland and dentistry students of the Medical University of Gdansk. The results obtained were statistically analyzed. The results were considered statistically significant if the condition $p \leq 0.05$ was met. Results: A total of 203 respondents participated in this survey. A total of $94.6 \%$ of them declared knowledge of the term MRONJ. However, the length of bisphosphonates persistence in the body was known to $51.5 \%$ of participants, while the knowledge of oral and maxillofacial surgeons concerning this topic was significantly higher $(87.0 \%)$. Conclusion: Dental and maxillofacial surgeons presented the highest level of knowledge about MRONJ. The remaining groups did not differ in their knowledge. It must be noted that the knowledge of the students was similar to that of dentists. A better level of knowledge by dentists could contribute to a decline of the occurrence of the disease in future. Theoretical and practical initiatives should be promoted to improve the knowledge about MRONJ.
\end{abstract}

Keywords: osteonecrosis; bisphosphonates; antiresorptive agents; awareness; knowledge; dentist

\section{Introduction}

Dentists are increasingly confronted with the occurrence of Medication-related Osteonecrosis of the Jaw (MRONJ), which is a serious complication in the treatment of diseases characterized by an excessive bone resorption. Antiresorptive drug therapy is currently widely used in treatment of patients suffering from osteoporosis, Paget's disease and osteogenesis imperfecta, as well as in the treatment and prevention of neoplastic metastases associated with breast, prostate and lung cancer and multiple myeloma. According to the current literature, medication-related osteonecrosis of the jaw is a serious complication not only in the therapy using drugs belonging to the bisphosphonate group, but also with denosumab and angiogenesis inhibitors [1-4]. Due to this, in 2014, the American Association of Oral and Maxillofacial Surgeons (AAOMS) proposed changing the term from Bisphosphonate Related Osteonecrosis of the Jaw (BRONJ) to Medication-Related Osteonecrosis of the Jaw (MRONJ) [1].

As of today, no effective methods of treating MRONJ have been developed; therefore, the prevention of this disease is of key importance [5,6]. Prophylactic management is determined by the prior assessment of the risk level of MRONJ and the type and duration of antiresorptive treatment [2,7-10]. Prior to the commencement of antiresorptive treatment, regardless of their 
respective risk group, patients should undergo a comprehensive dental examination, including radiological diagnostics, and receive oral hygiene instructions [2-4,11,12].

Dentists should be prepared to treat patients at risk of medication-related osteonecrosis of the jaw and they may be the first physicians able to recognize the initial symptoms of MRONJ. Current knowledge about this disease is essential in the work of a dentist. The literature on the awareness of dentists and students of dentistry is scarce [13-19]. The aim of this study was to assess the level of knowledge and awareness regarding MRONJ among Polish dentists and students of dentistry.

\section{Materials and Methods}

This descriptive cross-sectional study was performed using a web-based structured questionnaire among dental professionals working in Poland as well as 4th and 5th year dental students of the Medical University of Gdansk (MUG). The online self-administered questionnaire including a cover letter explaining the purpose of study was sent out electronically in March 2020. Answers were obtained until the end of September 2020. The anonymous survey consisted of two parts: part I evaluated the demographic and professional data including age, years of experience, specialization and a type of working sector; part II assessed knowledge about MRONJ. To maintain total confidentiality, participants were not required to write down their names in the questionnaire. The study included 103 dentists from multiple cities in Poland and 100 dentistry students of the MUG (Appendix A).

\section{Statistical Analysis}

In order to implement the premise of the study, a statistical analysis of the collected data was used. It was conducted by means of Statistica software, version 13.1 PL. The general characteristics of the information collected in the questionnaire were determined with the help of frequency statistics, i.e., the number of cases that meet a particular condition and the calculation of their percentage share in relation to the total number of respondents.

Additionally, the general knowledge score, as the sum of the correct answers, was calculated for each subject. The resulting variable was subjected to the analysis of the normality of the distribution, which was carried out by means of the Kolmogorov-Smirnow and W Shapiro-Wilk tests. Intergroup comparisons in terms of variables whose results were described on the nominal scale (correct or wrong answer to the survey question) were made by means of the Pearson chi-square test of independence. Parametric tests were used for the quantitative variable, which was the point knowledge score. Student's t-test was used for comparisons between two independent groups and, for comparisons of more independent groups $(\mathrm{k}>2)$, a one-way ANOVA $\mathrm{F}$ test was used. If a statistically significant result was found, a post hoc analysis was performed by means of the Scheffe test. The level of 83 statistical significance in the study was alpha $(\alpha)=0.05$. This means that the results of the 84 analyses were considered statistically significant if the condition $p \leq 0.05$ was met.

\section{Results}

All participants were divided into four groups to evaluate their knowledge about $\mathrm{BP}$ and MRONJ. The first group (group G1) included oral and maxillofacial surgeons, the second group (group G2) consisted of other specialists in dentistry and the third group (group G3) comprised of general dental practitioners. The fourth group (group G4) included dentistry students in the 4th and 5th year of the MUG's. Figure 1 presents the distribution of all participants who responded to the survey. The ratio of dentists belonging to group G2, that is: specialists in fields other than dental surgery and maxillofacial surgery, in presented in Figure 2. The participants, with the exception of students, were further divided into work sectors (Figure 3 ) and according to years of experience (Table 1).

The results of the survey of dentists and dental students concerning the knowledge about BP, MRONJ and assessing behavior in clinical situations are shown in Tables 1-5. 


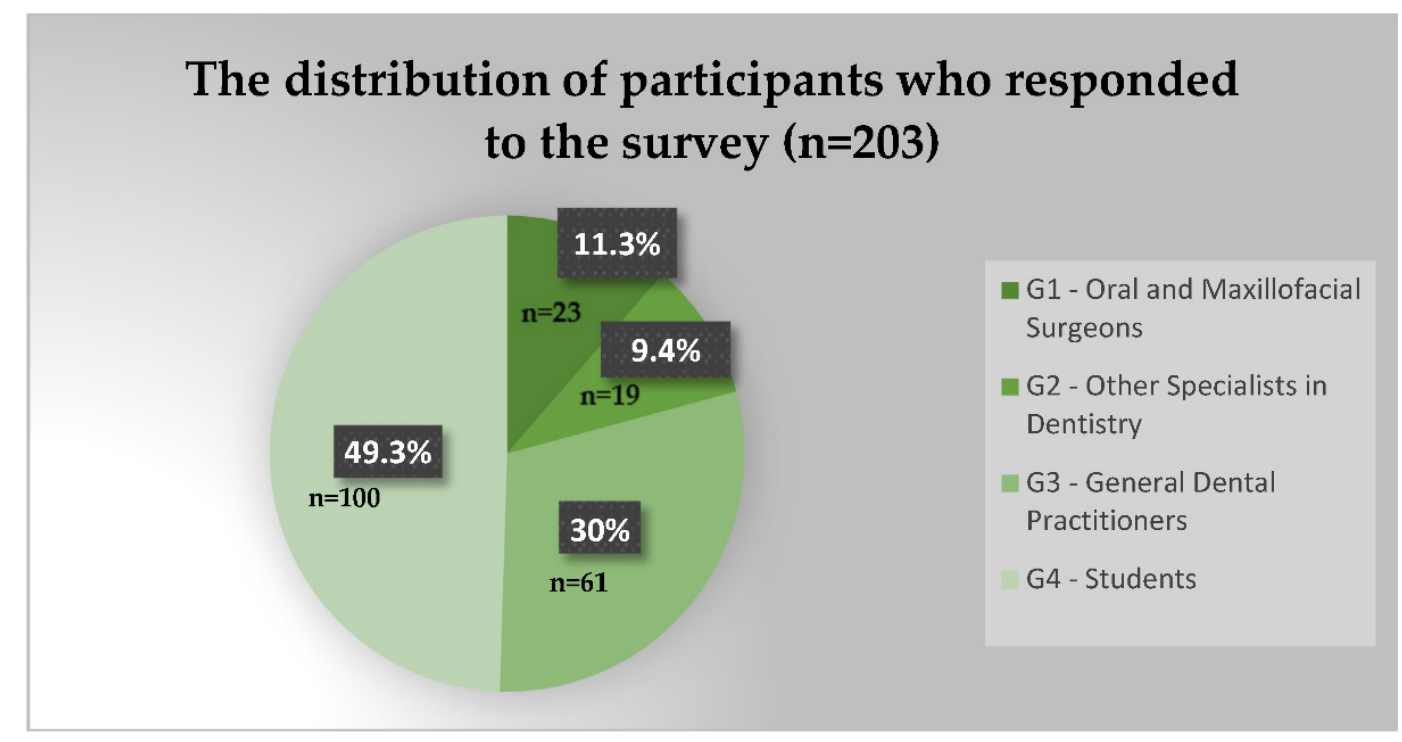

Figure 1. The distribution of participants who responded to the survey.

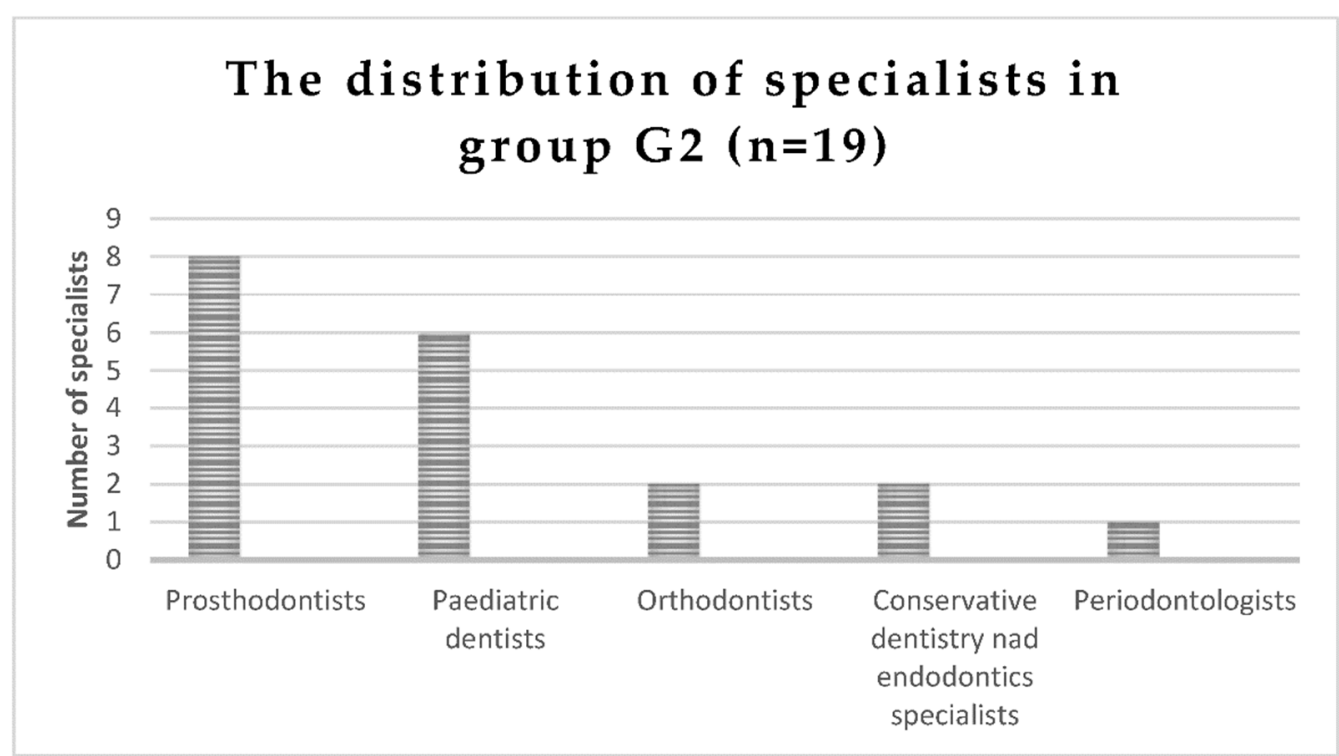

Figure 2. The number of the specialists in fields other than dental surgery and maxillofacial surgery (group G2).

Among the 200 respondents, $94.6 \%$ of them declared knowledge of the term MRONJ, and in their clinical practice less than half of the respondents $(47.0 \%)$ encountered medicationrelated osteonecrosis of the jaw. A total of $69.7 \%$ correctly defined the clinical picture of osteopathy visible in the oral cavity, including $82.6 \%$ from the G1 group, who are specialists in the field of dental and maxillofacial surgery. In the remaining groups, the number of correct answers to this question is lower and amounts to: G2-63.2\%, G3-66.7\%, G4-67.7\% (Table 1).

Only $60.9 \%$ oral and maxillofacial surgeons (G1) were aware of drugs correlated with Medication-Related Osteonecrosis of the Jaw, whereas the knowledge of the rest of the participants was at a significantly lower level. It is disturbing to note a very low level of knowledge among dentists who work in the private sector-only $16.0 \%$. It must be noted that dentists who work exclusively in the private sector also encounter MRONJ more rarely $(24.0 \%)$ in their practice than their colleagues working in both the public and private sector $(64.6 \%)$ and their knowledge of MRONJ symptoms is lower (58.0\%) (Table 1). 


\section{Division of dentists participating in the survey depending on their professional field $(n=100)$}

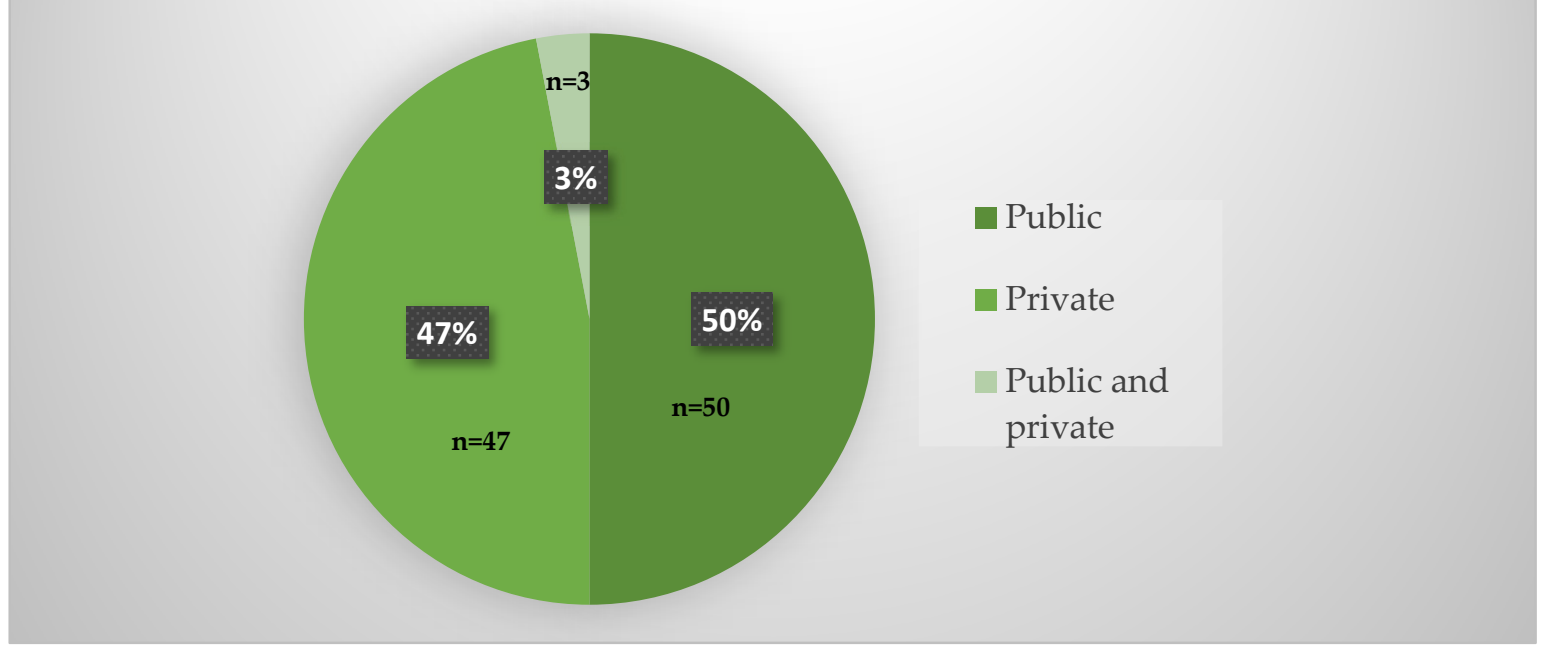

Figure 3. Division of dentists participating in the survey depending on their professional field.

Most of the participants knew the principal disease entities treated with BP such as osteoporosis, bone metastases and multiple myeloma. Besides the above mentioned diseases, the less-frequently known osteogenesis imperfecta was not recognized as well (Table 2).

Most of the participants were aware of how to administer BP-oral and IV (93.1\%) and of the necessity of oral sanitation before BP treatment is fundamental (96.0\%) (Table 3). The importance of referral to the dentists before BP therapy were perceived by $95.7 \%$, $94.7 \%, 93.3 \%$ and $96.0 \%$ of groups G1, G2, G3 and G4, respectively. However, the length of BP persistence, which is predicted as up to 10 years in the organism, were known in less than 50\% in groups G2 (42.1\%) and G3 (36.7\%), slightly more in group G4 (52.5\%), whilst the knowledge of oral and maxillofacial surgeons (group G1) about this topic was significantly higher and $87.0 \%$ of respondents in this group gave the correct answer to this question.

When asked about the increased risk of MRONJ in the case of intravenous (IV) administration of BP, 58.9\% of all participants gave the correct answer. Moreover, taking into account the specialization of the respondents, as many as $91.3 \%$ of surgeons answered this question correctly. In the remaining groups the results were lower, G2-42.1\%, G3-53.3\%, G4-57.6\%, respectively. Interestingly, the results of the analysis of the survey showed that $34.2 \%$ of the study participants admitted that they did not know the answer, and $6.9 \%$ answered incorrectly.

Furthermore, participants presented their knowledge regarding MRONJ-treatment recommendations, risk factors and guidelines (Tables 4 and 5). Periodontal disease (93.1\%) and poor oral hygiene (93.1\%) was the best recognized risk factor of MRONJ. However, only below $60 \%$ of the dentists in groups G2 and G3 and students knew the importance of the way of BP administration for MRONJ occurrence. Dental specialists in oral and maxillofacial surgery showed better comprehensive knowledge of risk factors, but insufficient for steroid therapy and tobacco use. It is surprising that only $37.4 \%$ of students pointed to alcohol as an incorrect answer, which is the lowest result among all examined groups. Detailed results are shown in Table 4. 
Table 1. General knowledge about MRONJ.

\begin{tabular}{|c|c|c|c|c|c|c|c|c|c|c|c|c|c|}
\hline \multirow{2}{*}{$\begin{array}{l}\text { General Knowledge } \\
\text { about MRONJ }\end{array}$} & \multirow{2}{*}{$\begin{array}{c}\text { Total } \\
(n=200)\end{array}$} & \multicolumn{5}{|c|}{ Examined Groups: } & \multicolumn{4}{|c|}{ The Duration of Work experience (Years): } & \multicolumn{3}{|c|}{ Dentists in Work Sector: } \\
\hline & & $\begin{array}{c}\mathrm{G} 1 \\
(n=23)\end{array}$ & $\begin{array}{c}\mathrm{G} 2 \\
(n=19)\end{array}$ & $\begin{array}{c}\mathrm{G} 3 \\
(n=60)\end{array}$ & $\begin{array}{c}\mathrm{G} 4 \\
(n=98)\end{array}$ & $p$ & $<1 y(n=4)$ & $\begin{array}{c}1-10 y \\
(n=79)\end{array}$ & $\begin{array}{l}11-20 y \\
(n=17)\end{array}$ & $p$ & $\begin{array}{c}\text { Public and } \\
\text { Private }(n=50)\end{array}$ & $\begin{array}{l}\text { Private } \\
(n=47)\end{array}$ & $p$ \\
\hline $\begin{array}{l}\text { Participants (\%) familiar } \\
\text { with definition of MRONJ }\end{array}$ & $94.6 \%$ & $100 \%$ & $100 \%$ & $86.7 \%$ & $97.0 \%$ & 0.014 & $100 \%$ & $89.9 \%$ & $100 \%$ & NS & $93.8 \%$ & $90.0 \%$ & NS \\
\hline $\begin{array}{l}\text { Participants }(\%) \text { who } \\
\text { encountered MRONJ in } \\
\text { practice }\end{array}$ & $47.0 \%$ & $87.0 \%$ & $42.1 \%$ & $28.3 \%$ & $51.0 \%$ & 0.00003 & $25.0 \%$ & $43.0 \%$ & $52.9 \%$ & NS & $64.6 \%$ & $24.0 \%$ & 0.00005 \\
\hline $\begin{array}{c}\text { Participants (\%) who } \\
\text { know the symptoms of } \\
\text { MRONJ }\end{array}$ & $69.7 \%$ & $82.6 \%$ & $63.2 \%$ & $66.7 \%$ & $67.7 \%$ & NS & $100 \%$ & $69.6 \%$ & $58.8 \%$ & NS & $79.2 \%$ & $58.0 \%$ & 0.02429 \\
\hline $\begin{array}{l}\text { Participants }(\%) \text { who } \\
\text { know drugs which are } \\
\text { responsible for the risk of } \\
\text { developing MRONJ }\end{array}$ & $33.7 \%$ & $60.9 \%$ & $31.6 \%$ & $26.7 \%$ & $30.3 \%$ & 0.02298 & $50.0 \%$ & $36.7 \%$ & $23.5 \%$ & NS & $54.2 \%$ & $16.0 \%$ & 0.00007 \\
\hline
\end{tabular}

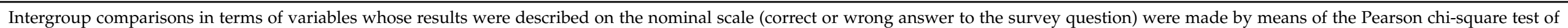
independence. NS-non-significant.

Table 2. Answers to the question concerning the diseases treated with bisphosphonates.

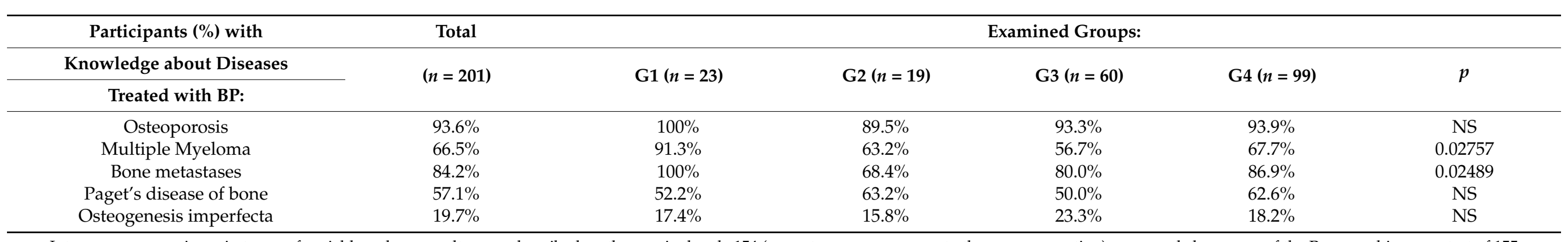

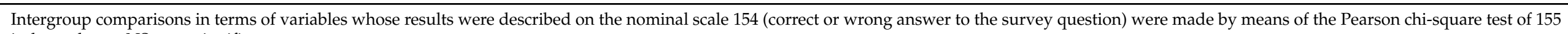
independence. NS-nonsignificant. 
Table 3. General knowledge about bisphosphonates.

\begin{tabular}{|c|c|c|c|c|c|c|}
\hline \multirow{2}{*}{$\begin{array}{l}\text { Correct Answers of the Participants } \\
\text { (\%) to Questions Concerning: }\end{array}$} & \multirow{2}{*}{ Total $(n=202)$} & \multicolumn{5}{|c|}{ Examined Groups: } \\
\hline & & G1 $(n=23)$ & G2 $(n=19)$ & $\mathrm{G} 3(n=60)$ & $\mathrm{G} 4(n=100)$ & $p$ \\
\hline BP's administration (oral and IV) & $93.1 \%$ & $100 \%$ & $89.5 \%$ & $88.3 \%$ & $93.9 \%$ & NS \\
\hline $\begin{array}{c}\text { Dental check before BP treatment } \\
\text { (Yes) }\end{array}$ & $96.0 \%$ & $95.7 \%$ & $94.7 \%$ & $93.3 \%$ & $96.0 \%$ & NS \\
\hline $\begin{array}{l}\text { Length of BP persistence in the } \\
\text { organism (10 years) }\end{array}$ & $51.5 \%$ & $87.0 \%$ & $42.1 \%$ & $36.7 \%$ & $52.5 \%$ & 0.00055 \\
\hline $\begin{array}{l}\text { Greater risk of MRONJ due to oral } \\
\text { administration versus intravenous } \\
\text { (IV is higher) }\end{array}$ & $58.9 \%$ & $91.3 \%$ & $42.1 \%$ & $53.3 \%$ & $57.6 \%$ & 0.00462 \\
\hline
\end{tabular}

Intergroup comparisons in terms of variables whose results were described on the nominal scale (correct or wrong answer to the survey question) were made by means of the Pearson chi-square test of independence. NS—nonsignificant.

Table 4. Risk factors of MRONJ.

\begin{tabular}{|c|c|c|c|c|c|c|}
\hline \multirow{2}{*}{$\begin{array}{l}\text { Answers of Participants (\%) to the } \\
\text { Question about of MRONJ Risk Factors }\end{array}$} & \multirow{2}{*}{ Total $(n=202)$} & \multicolumn{5}{|c|}{ Examined Groups: } \\
\hline & & G1 $(n=23)$ & G2 $(n=19)$ & G3 $(n=60)$ & $\mathrm{G} 4(n=100)$ & $p$ \\
\hline Poor Oral Hygiene (correct) & $93.1 \%$ & $100 \%$ & $84.2 \%$ & $95.0 \%$ & $91.9 \%$ & NS \\
\hline Periodontal Disease (correct) & $93.1 \%$ & $100 \%$ & $84.2 \%$ & $95.0 \%$ & $91.9 \%$ & NS \\
\hline Denture wearing (correct) & $82.3 \%$ & $78.3 \%$ & $79.0 \%$ & $81.7 \%$ & $83.8 \%$ & NS \\
\hline Tobacco use (correct) & $80.8 \%$ & $65.2 \%$ & $84.2 \%$ & $80.0 \%$ & $83.8 \%$ & NS \\
\hline Steroid therapy (correct) & $54.7 \%$ & $43.5 \%$ & $63.2 \%$ & $50.0 \%$ & $58.6 \%$ & NS \\
\hline Length of therapy (>3y) & $75.9 \%$ & $87.0 \%$ & $79.0 \%$ & $73.3 \%$ & $74.8 \%$ & NS \\
\hline Manner of administration (IV) & $56.7 \%$ & $82.6 \%$ & $57.9 \%$ & $53.3 \%$ & $52.5 \%$ & NS \\
\hline Hypertension (incorrect) & $84.7 \%$ & $95.7 \%$ & $79.0 \%$ & $88.3 \%$ & $81.8 \%$ & NS \\
\hline Hyperlipidemia (incorrect) & $80.3 \%$ & $91.3 \%$ & $84.2 \%$ & $78.3 \%$ & $77.8 \%$ & NS \\
\hline Alcohol (incorrect) & $47.3 \%$ & $60.9 \%$ & $57.9 \%$ & $55.0 \%$ & $37.4 \%$ & 0.04822 \\
\hline
\end{tabular}

Intergroup comparisons in terms of variables whose results were described on the nominal scale (correct or wrong answer to the survey question) were made by means of the Pearson chi-square test of independence. NS-nonsignificant.

Table 5. The knowledge about MRONJ.

\begin{tabular}{|c|c|c|c|c|c|c|}
\hline \multirow[b]{2}{*}{ Knowledge about MRONJ } & \multirow[b]{2}{*}{$\begin{array}{l}\text { Total }\left(n^{1}=200\right) \\
\quad\left(n^{2}=201\right)\end{array}$} & \multicolumn{5}{|c|}{ Examined Groups: } \\
\hline & & $\mathrm{G} 1(n=23)$ & G2 $(n=19)$ & G3 $(n=60)$ & $\begin{array}{c}\mathrm{G} 4\left(n^{1}=97\right) \\
\left(n^{2}=98\right)\end{array}$ & $p$ \\
\hline Participants (\%) who declare that they & & & & & & \\
\hline $\begin{array}{l}\text { know the guidelines of MRONJ } \\
\text { treatment }\end{array}$ & $55.2 \%$ & $87.0 \%$ & $26.3 \%$ & $41.7 \%$ & $60.8 \%$ & 0.00009 \\
\hline $\begin{array}{l}\text { Participants (\%) who want to know } \\
\text { more about MRONJ }\end{array}$ & $96.0 \%$ & $95.7 \%$ & $89.5 \%$ & $96.7 \%$ & $98.0 \%$ & NS \\
\hline
\end{tabular}

Intergroup comparisons in terms of variables whose results were described on the nominal scale (correct or wrong answer to the survey question) were made by means of the Pearson chi-square test of independence. NS-nonsignificant. $n^{1}$-Number of participants who answered the question: "Do you know the guidelines for managing patients at risk of developing MRONJ?". $n^{2}-$ Number of participants who answered the question: "Would you like to know more about MRONJ?".

Only a little more than half of surveyed participants (55.2\%) declare that they know the guidelines of MRONJ treatment (Table 5). In the results there is a visible disproportion in answers to this question between groups G1 and G2. The acquaintance of guidelines for the treatment and prophylaxis of MRONJ were declared by $87.0 \%$ of the surveyed specialists in the field of dental and maxillofacial surgery (group G1). However, specialists in other fields of dentistry (group G2) achieved the lowest results, which means that only $26.3 \%$ of dentists in this group declare knowledge of these guidelines. It is encouraging that $96.0 \%$ of the study participants would like to know more about MRONJ (Table 5). 


\section{Discussion}

To the best of our knowledge, this is the first study assessing MRONJ knowledge among dental practitioners and dentistry students from Poland. Comparing the obtained results with those from similar studies carried out in other countries, responses of participants in our study are on a satisfactory level and stand out positively compared to other surveys $[13,15,19,20]$.

On the basis of the survey, $94.6 \%$ of respondents stated that they know the term MRONJ, which is the highest result among other studies conducted so far. Jaw-bone osteonecrosis associated with the use of bisphosphonates and other antiresorptive drugs (MRONJ) is widely regarded as one of the most serious complications in the treatment of diseases characterized by an excessive bone resorption. Currently, there is no effective treatment for MRONJ and therefore the key is the prevention of this disease and the management of the recommended therapeutic strategies in relation to the advancement of MRONJ [5,6]. The results concerning the level of knowledge of MRONJ guidelines seem alarming, as only $26.3 \%$ of the surveyed dentists of other specialties (group G2) declared knowledge of these guidelines, and in the remaining groups (G3 and G4) the results are only slightly higher. Only specialists in the field of dental and maxillofacial surgery report a significantly higher degree of knowledge of procedures for the treatment of patients with this osteopathy $(87.0 \%)$. This may result from the specificity of the specialization, which is associated with a greater likelihood of contact with patients suffering from MRONJ. According to the results of the study, $87.0 \%$ of the surveyed dental and maxillofacial surgeons reported having prior contact with a patient with MRONJ symptoms.

It is also interesting that dentists working in the public sector show more knowledge in this area, which may be related to the implementation of specialization, which in Poland takes place mainly in the public sector. On the other hand, the study showed that seniority has no significant impact on the level of knowledge about MRONJ.

Due to the expansion of medical indications for therapy with bisphosphonates and other antiresorptive drugs (e.g., denosumab), the number of patients suffering from MRONJ has increased significantly $[1,21]$. The results show that although $94.6 \%$ of respondents know about the existence of such a disease, only 33.7\% know that BP, denosumab and angiogenesis inhibitors are drugs that increase the risk of MRONJ. In the research of Franchi, who assessed the knowledge of medical students in Italy in his study, out of 72 respondents, only $12(16.7 \%)$ possessed knowledge about the type of drugs that increased the risk of MRONJ [20]. Without this crucial knowledge about therapeutics, the risk of treatment complication is elevated. One third of the respondents indicated only bisphosphonates, which may be the result of the knowledge of the publication on bisphosphonate-related bone necrosis (BRONJ), which was first described in 2003 by Marx et al. [22]. However, in 2014, the AAOMS proposed the use of the term MRONJ due to the increasing number of reported cases of osteonecrosis of the jaws associated with other antiresorptive drugs [1]. According to the survey evaluating the awareness of MRONJ within the Birmingham GMP community, only $6 \%$ of participants were aware of change in terminology from BRONJ to MRONJ [23]. Without a thorough knowledge of drugs used in antiresorptive therapies, dentists may contribute to an increased risk of developing MRONJ by not following the recommendations in patients at risk of osteonecrosis of the jaws [3,24].

The 2014 AAOMS criteria indicate that a patient may be suspected of MRONJ if all of the following conditions are met: current antiresorptive or antiangiogenic drug therapy or past history of such treatment; exposure of the craniofacial bones or intra- or extraoral fistula in this area-lasting for more than 8 weeks; no history of radiation therapy to the jaws; no neoplastic metastases to the jaw bones [1]. Clinical signs may present a bare or necrotic jaw bone, pathological fracture, pain, inflammation, tooth mobility, intra- or extraoral fistula $[1,21,25]$. A total of $69.7 \%$ of the respondents correctly indicated the description of the clinical picture of MRONJ in the oral cavity, among which the vast majority of correct answers were provided by those specializing in surgery (82.6\%). Typically, osteonecrosis is caused by a preceding local infection or damage to the oral mucosa or bone [2,3]. The most 
frequently presented risk factors in the oral cavity are tooth extraction $(45 \%)$, periodontal disease $(10 \%)$ and poorly fitted removable prosthetic restorations [3,24,26,27].

Before starting antiresorptive treatment, patients should undergo a dental examination and receive oral hygiene instruction [2,4,11,12]. A total of 193 surveyed dentists and students of dentistry $(96.0 \%)$ are aware of the necessity of oral cavity sanitation before starting bisphosphonate treatment, which indicates the need for cooperation between doctors and dentists. Researchers in Brazil achieved a slightly lower result, where $87.69 \%$ and $84.59 \%$ of the dentists and physicians surveyed, respectively, indicated the importance of referral to a dentist before starting therapy with antiresorptive drugs [28]. In a UK study of general medical practitioners (GMPs), although more than half of them present a risk of MRONJ to their patients, only $32 \%$ consider referral to a dentist before prescribing antiresorptive drugs [23]. Researchers in Italy obtained much more promising results on this subject among students of the last two years of medicine. Almost all students (71 out of 72 respondents) replied that a dental examination was needed before starting bisphosphonate therapy [20]. Better education on this subject during medical studies may result in greater awareness of the prevention, risk factors and management of MRONJ among young physicians.

\section{Conclusions}

In our survey, dentists specializing in dental and maxillofacial surgery exhibited the highest degree of knowledge about MRONJ. The remaining groups did not differ in their level of knowledge between each other. The duration of work experience does not translate into greater knowledge about MRONJ. It is noteworthy that the dentists working in the private sector have less contact with patients suffering from MRONJ, which translates into a lower level of knowledge about this disease than the dentists working in both the public and private sector. It must be emphasized that the knowledge of the students was similar to that of practicing dentists. The quality of education received by the students of MUG on the topic of MRONJ is reasonably high. Providing students with adequate education about MRONJ could be major aspect of MRONJ prevention in the future.

Considering the results of the study, it is advisable to further promote the knowledge about prophylaxis and dental preparation of patients for the implementation of antiresorptive treatment, e.g., in the form of generally accessible trainings, studies or webinars. It is encouraging that the majority of respondents declared a desire to know more about MRONJ which, in turn, could contribute to a decline of the occurrence of the disease in the future.

Author Contributions: Conceptualization: M.T., H.S.; methodology M.T., H.S.; investigation M.T.; resources M.T., H.S.; data curation M.T., H.S.; writing—original draft preparation- M.T.; writingreview and editing, M.T., H.S., B.K.; visualization M.T.; Supervision B.D.; project administration I.O.-K., B.D., B.K. All authors have read and agreed to the published version of the manuscript.

Funding: This research received no external funding.

Institutional Review Board Statement: Not applicable.

Informed Consent Statement: Informed consent was obtained from all subjects involved in the study.

Data Availability Statement: The data presented in this study are available on request from the corresponding author.

Conflicts of Interest: The authors declare no conflict of interest.

\section{Appendix A}

Questionnaire-Awareness of Medication-Related Osteonecrosis of the Jaws amongst

Dental Professionals in Poland.

I General Information

1. Age 


$\begin{array}{ll}< & <25 \\ 0 & 25-35 \\ & 35-50 \\ & >50\end{array}$

2. Years of professional experience

$\begin{array}{ll}\bigcirc & <1 \\ 0 & 1-10 \\ 0 & 11-20 \\ 0 & >20 \\ & \text { Student }\end{array}$

3. Dental specialization

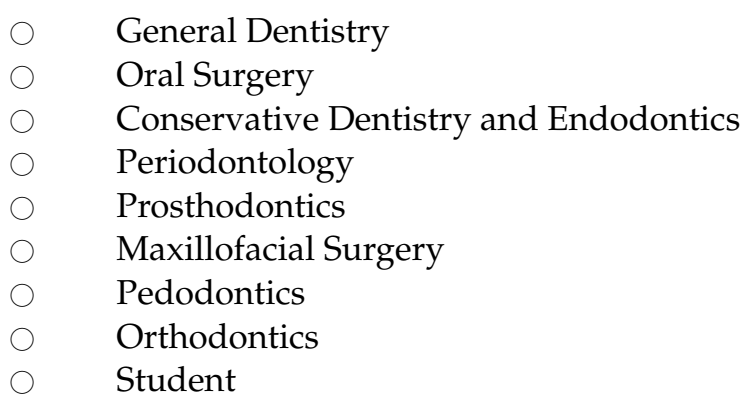

4. Work sector
Public
Private
Public and private
- Student

\section{General Knowledge about MRONJ}

1. In what diseases is bisphosphonate treatment used? (please mark all that apply)

Osteoporosis

Multiple myeloma

Cancer metastases to the bone

Anemia

Osteogenesis imperfecta

Paget's disease

Hypertension

2. In what way are bisphosphonates administered?
Intravenously
Orally
Intravenously and orally
I don't know

3. Is a dental examination and oral cavity sanitation necessary before starting bisphosphonate therapy?

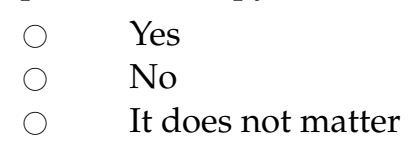

4. Are you familiar with the term MRONJ—Medication Related Osteonecrosis of the Jaw?

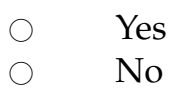

5. Which drugs are responsible for the risk of developing MRONJ?
Bisphosphonates
Bisphosphonates and Denosumab 
Bisphosphonates and Angiogenesis Inhibitors

$\bigcirc \quad$ Bisphosphonates, Denosumab and Angiogenesis Inhibitors

I do not know

6. What is the clinical picture of MRONJ in the oral cavity?

Exposed bone necrosis

Bone necrosis outbreak without bone exposure

Bone necrosis outbreak with or without bone exposure

I don't know

7. Do you know the guidelines for managing patients at risk of developing MRONJ?

Yes

$\bigcirc \quad$ No

8. Does oral ingestion of bisphosphonates carry a greater risk of developing MRONJ than if administered intravenously?

Yes

No

I don't know

9. How long after completing bisphosphonate therapy are bisphosphonates present in the organism?
Up to 1 month
Up to 6 months
Up to 1 year
Up to 10 years

10. Do you know what are the risk factors for MRONJ? (please mark all that apply)

Alcohol

Smoking cigarettes

Poor oral hygiene

Periodontal disease

Poorly fitted removable prosthetic restorations

Hyperlipidemia

Steroid therapy

Length of therapy

Method of administration (oral/intravenous)

Hypertension

11. Have you encountered MRONJ in your practice?

$\begin{array}{ll}\bigcirc & \text { Yes } \\ 0 & \text { No }\end{array}$

12. Would you like to know more about MRONJ?

Yes

No

I do not know

\section{References}

1. Ruggiero, S.L.; Dodson, T.B.; Fantasia, J.; Goodday, R.; Aghaloo, T.; Mehrotra, B.; O’Ryan, F. American Association of Oral and Maxillofacial Surgeons Position Paper on Medication-Related Osteonecrosis of the Jaw-2014 Update. J. Oral Maxillofac. Surg. 2014, 72, 1938-1956. [CrossRef]

2. Nicolatou-Galitis, O.; Schiødt, M.; Mendes, R.A.; Ripamonti, C.; Hope, S.; Drudge-Coates, L.; Niepel, D.; Wyngaert, T.V.D. Medication-related osteonecrosis of the jaw: definition and best practice for prevention, diagnosis, and treatment. Oral Surg. Oral Med. Oral Pathol. Oral Radiol. 2019, 127, 117-135. [CrossRef] [PubMed]

3. Di Fede, O.; Panzarella, V.; Mauceri, R.; Fusco, V.; Bedogni, A.; Muzio, L.L.; Board, S.O.; Campisi, G. The Dental Management of Patients at Risk of Medication-Related Osteonecrosis of the Jaw: New Paradigm of Primary Prevention. BioMed Res. Int. 2018, 2018, 1-10. [CrossRef] [PubMed] 
4. Muthukrishnan, A.; Kumar, L.B.; Ramalingam, G. Medication-related osteonecrosis of the jaw: a dentist's nightmare. BMJ Case Rep. 2016, 2016, 1-7. [CrossRef]

5. Beth-Tasdogan, N.H.; Mayer, B.; Hussein, H.; Zolk, O. Interventions for managing medication-related osteonecrosis of the jaw. Cochrane Database Syst. Rev. 2017, 10, CD012432. [CrossRef] [PubMed]

6. Fehm, T.; Felsenberg, D.; Krimmel, M.; Solomayer, E.; Wallwiener, D.; Hadjii, P. Bisphosphonate-associated osteonecrosis of the jaw in breast cancer patients: Recommendations for prevention and treatment. Breast 2009, 18, 213-217. [CrossRef] [PubMed]

7. Yoneda, T.; Japanese Allied Committee on Osteonecrosis of the Jaw; Hagino, H.; Sugimoto, T.; Ohta, H.; Takahashi, S.; Soen, S.; Taguchi, A.; Nagata, T.; Urade, M.; et al. Antiresorptive agent-related osteonecrosis of the jaw: Position Paper 2017 of the Japanese Allied Committee on Osteonecrosis of the Jaw. J. Bone Miner. Metab. 2016, 35, 6-19. [CrossRef]

8. Papi, P.; Rosella, D.; Giardino, R.; Cicalini, E.; Piccoli, L.; Pompa, G. Medication-related osteonecrosis of the jaw: Clinical and practical guidelines. J. Int. Soc. Prev. Community Dent. 2016, 6, 97-104. [CrossRef] [PubMed]

9. Stewart, D.L. Prosthodontic treatment of a patient taking nitrogen-containing bisphosphonates to preserve the integrity of the epithelial attachment: A clinical report. J. Prosthet. Dent. 2011, 106, 350-354. [CrossRef]

10. Jacobsen, C.; Zemann, W.; Obwegeser, J.A.; Grätz, K.W.; Metzler, P. The phosphorous necrosis of the jaws and what can we learn from the past: a comparison of "phossy" and "bisphossy" jaw. Oral Maxillofac. Surg. 2012, 18, 31-37. [CrossRef]

11. Campisi, G.; Fedele, S.; Fusco, V.; Pizzo, G.; Di Fede, O.; Bedogni, A. Epidemiology, clinical manifestations, risk reduction and treatment strategies of jaw osteonecrosis in cancer patients exposed to antiresorptive agents. Futur. Oncol. 2014, 10, 257-275. [CrossRef] [PubMed]

12. Coleman, R.; Body, J.J.; Aapro, M.; Hadji, P.; Herrstedt, J. Bone health in cancer patients: ESMO Clinical Practice Guidelines. Ann. Oncol. 2014, 25, iii124-iii137. [CrossRef] [PubMed]

13. Rosella, D.; Papi, P.; Pompa, G.; Capogreco, M.; De Angelis, F.; Di Carlo, S. Dental students' knowledge of medication-related osteonecrosis of the jaw. Eur. J. Dent. 2017, 11, 461-468. [CrossRef]

14. Al Abdullateef, A.Y. Awareness of Medication-Related Osteonecrosis of the Jaw (MRONJ) among oncology dental patients with risk factors for MRONJ. Master's Thesis, The Graduate School of the University at Buffalo, State University of New York, New York, NY, USA, 2016.

15. Al-Maweri, S.A.; Alshammari, M.N.; Alharbi, A.R.; Bahein, A.A.; Alhajj, M.N.; Al-Shamiri, H.M.; Alahmary, A.W.; Doumani, M. Knowledge and Opinions of Saudi Dentists Regarding Dental Treatment of Patients Undergoing Bisphosphonates. Eur. J. Dent. 2020, 14, 144-151. [CrossRef] [PubMed]

16. Tanna, N.; Steel, C.; Stagnell, S. AWARENESS OF MEDICATION RELATED OSTEONECROSIS OF THE JAW AMONGST DENTISTS AND DOCTORS IN THE UK. Oral Surg. Oral Med. Oral Pathol. Oral Radiol. 2017, 124, e193. [CrossRef]

17. Al-Samman, A.A.; Al-Ani, R.S. Across-sectional survey on medication-related osteonecrosis of the jaws' knowledge and awareness in a sample of dental society. J. Cranio-Maxillofac. Surg. 2019, 47, 926-931. [CrossRef]

18. Patil, V.; Acharya, S.; Vineetha, R.; Nikhil, K. Awareness about medication-related osteonecrosis of the jaw among dental professionals: A multicenter study. Oral Heal. Prev. Dent. 2020, 18, 505-509. [CrossRef]

19. Al-Eid, R.; Alduwayan, T.; Bin Khuthaylah, M.; Al Shemali, M. Dentists' knowledge about medication-related osteonecrosis of the jaw and its management. Heliyon 2020, 6, e04321. [CrossRef]

20. Franchi, S.; Brucoli, M.; Boffano, P.; Dosio, C.; Benech, A. Medical students' knowledge of medication related osteonecrosis of the jaw. J. Stomatol. Oral Maxillofac. Surg. 2020, 121, 344-346. [CrossRef]

21. Eguia, A.; Bagán-Debón, L.; Cardona, F. Review and update on drugs related to the development of osteonecrosis of the jaw. Medicina Oral Patol. Oral y Cir. Bucal 2020, 25, e71-e83. [CrossRef]

22. E Marx, R. Pamidronate (Aredia) and zoledronate (Zometa) induced avascular necrosis of the jaws: A growing epidemic J. Oral Maxillofac. Surg. 2003, 61, 1115-1117. [CrossRef]

23. Rahman, Z.; Nayani, S.; Anstey, H.; Murphy, M. A survey evaluating the awareness of MRONJ within the Birmingham GMP community. Oral Surg. 2018, 12, 22-29. [CrossRef]

24. McGowan, K.; McGowan, T.; Ivanovski, S. Risk factors for medication-related osteonecrosis of the jaws: A systematic review. Oral Dis. 2018, 24, 527-536. [CrossRef] [PubMed]

25. Dunphy, L.; Salzano, G.; Gerber, B.; Graystone, J. Medication-related osteonecrosis (MRONJ) of the mandible and maxilla. BMJ Case Rep. 2020, 13, e224455. [CrossRef]

26. Göllner, M.; Holst, S.; Fenner, M.; Schmitt, J. Prosthodontic treatment of a patient with bisphosphonate-induced osteonecrosis of the jaw using a removable dental prosthesis with a heat-polymerized resilient liner: A clinical report. J. Prosthet. Dent. 2010, 103, 196-201. [CrossRef]

27. Hasegawa, Y.; Kawabe, M.; Kimura, H.; Kurita, K.; Fukuta, J.; Urade, M. Influence of dentures in the initial occurrence site on the prognosis of bisphosphonate-related osteonecrosis of the jaws: A retrospective study. Oral Surg. Oral Med. Oral Pathol. Oral Radiol. 2012, 114, 318-324. [CrossRef] [PubMed]

28. Miranda-Silva, W.; Montezuma, M.A.; Benites, B.M.; Bruno, J.S.; Fonseca, F.P.; Fregnani, E.R. Current knowledge regarding medication-related osteonecrosis of the jaw among different health professionals. Support. Care Cancer 2020, 28, 5397-5404. [CrossRef] 